\title{
Radiodifusão: dispositivo intersetorial na produção de saúde ${ }^{1}$
}

Broadcasting: intersectoral contrivance in the production of health

Radiodifusión: dispositivo intersectorial en la producción de salud

\section{Ariane Marinho Santana}

Grupo Hospitalar Conceição, Porto Alegre, RS, Brasil. Carlos Alberto Severo Garcia Júnior

Grupo Hospitalar Conceição, Porto Alegre, RS, Brasil.

Mário Francis Petry Londero

Grupo Hospitalar Conceição, Porto Alegre, RS, Brasil. Milene Calderaro Martins

Grupo Hospitalar Conceição, Porto Alegre, RS, Brasil.

Michele dos Santos Ramos Lewis

Grupo Hospitalar Conceição, Porto Alegre, RS, Brasil.

Renato Luiz Rieger da Nova

Grupo Hospitalar Conceição, Porto Alegre, RS, Brasil.

\section{Resumo}

O artigo trata do cuidado intersetorial na saúde, sendo feito por usuários e trabalhadores participantes de um programa de rádio. A escrita volta-se às memórias dos programas ocorridos, buscando, nesse olhar para trás, um vigor para a discussão. Percorre-se toda uma trajetória de construção do cuidado, inspirado no modo de apresentação do programa de rádio. $\mathrm{O}$ artigo tem estrutura semelhante ao programa, contendo subtítulos iguais aos blocos do mesmo. Num primeiro momento apresentaremos o programa, onde está inserido e os atores vinculados. No bloco 1 resgataremos um pouco da história da Reforma Psiquiátrica e as relações com a PNH. No bloco 2 debateremos o cuidado em saúde intersetorial. O terceiro bloco serão memórias do Coletivo loucutor, as quais trarão para o texto pensamentos sobre o fazer radiofônico e o cuidado em saúde. Finalizaremos com as dicas do dia, assim como fazemos no último bloco do programa.

Palavras-chave: Radiodifusão, Produção de Saúde, Saúde Mental, Intersetorialidade, Loucutores. 


\begin{abstract}
This article deals with the intersectoral health care, by the users and workers' view trough participation in a radio program. Writing back the memories of the programs occurred, searching, looking back at that, a place for discussion. Scrolls through an entire career building care, inspired by the presentation mode of the radio program. The article has a structure similar to the program, containing subtitles equal to the blocks thereof. At first we will present the program, which is housed and linked actors. In block 1 will redeem some of the history of psychiatric reform and relations with PNH. In block 2 will discuss the intersectoral health care. The third block constitutes the "loucutor-collective's memories", which will bring the text thoughts about doing radio and healthcare. Conclude with the tips of the day, as we used do in the last block of the program.
\end{abstract}

Keywords: Broadcasting, Health Production, Mental Health, Intersectoral, "Loucutores".

\title{
Resumen
}

El presente artículo aborda la atención intersectorial de la salud que realizan los usuarios y de los trabajadores que participan en un programa de radio. Escritura de vuelta, los recuerdos de los programas ocurrido, buscando, mirando hacia atrás en eso, un lugar para el debate. Se desplaza a través de un cuidado carrera edificio, inspirado en el modo de presentación del programa de radio. El artículo tiene una estructura similar a la del programa, que contiene subtítulos iguales a los bloques de los mismos. En un primer momento vamos a presentar el programa, donde se encuentra y los actores vinculados. En el bloque 1, presentamos parte de la historia de la reforma psiquiátrica y las relaciones con PNH. En el bloque 2 se discutirá el cuidado de la salud intersectorial. El tercer bloque presentamos las memorias colectivas de los "loucutores", que llevarán para el texto los pensamientos de los modos de cómo hacer radio y en el cuidado de la salud. Llegaremos a la conclusión del artículo con las sugerencias del día, como lo hacemos en el último bloque del programa. 
Palabras Clave: Radiodifusión, Producción de Salud, Salud Mental, intersectorial, "Loucutores".

\section{Música de Abertura no Ar: Uma Breve Introdução}

Este artigo vem tratar da potência em produzir saúde numa dimensão de cuidado transversal, isto é, numa zona de indefinição das forças que atravessa os sujeitos e a instituição saúde nos processos de subjetivação que estão em jogo e que mutuamente se transformam, extrapolando os limites do pensar a atenção em saúde ao abarcar a sua extensão política e relacional junto a outros setores da vida. Pensar a saúde atrelada a outros setores exige um pensar clínico ampliado, na intenção de produzir um cuidado que abranja a singularidade de cada usuário em questão. Nesse sentido, se impõem dois pontos importantes para a sua ampliação: a construção de sistemas integrados de saúde e a articulação de um conjunto de iniciativas e ações intersetoriais em um território (Brasil, 2009a).

É no âmbito das ações de cuidado intersetoriais, voltadas para os territórios existenciais de cada pessoa que está em atendimento junto a algum serviço de saúde, que apresentamos a construção e articulação de um espaço coletivo de radiodifusão na prática cotidiana da clínica. Assim, exporemos a produção de um programa de rádio como dispositivo para ações intersetoriais entre saúde e cultura, que parece dar passagem a uma vida mais potente aos sujeitos participantes a partir das discussões pautadas a cada encontro, com as trocas de saberes e de afecções que confabulam encontros cercados por uma "comunicação terapeutizante" (Moreira, 2011).

O programa aqui apresentado se chama Quartas Intenções: um encontro real com seus amigos imaginários, ele é realizado nas ondas sonoras que percorrem a região norte de Porto Alegre a partir de uma rádio comunitária. Em abril de 2010 foi feito um convite para se criar um programa de rádio ligado à rede de saúde mental do Grupo Hospitalar Conceição $\left(\mathrm{GHC}^{2}\right)$. Esse convite partiu das aproximações com a comunidade do Bairro Rubem Berta e do Ponto de Cultura "Falando a gente se entende" situado na região, o qual está vinculado a Associação de moradores do Conjunto Habitacional Rubem Berta (AMORB), 
em Porto Alegre. A associação fora fundada em 1987, com a Rádio Comunitária sendo iniciada em 2007, no intuito de dar condições à comunidade de ter um canal de comunicação inteiramente dedicado a ela, abrindo oportunidades para a divulgação de suas ideias.

Partindo desse contexto, pensamos que a nossa inserção como radialistas amadores seria relevante por articular os recursos intersetoriais do próprio território de vida dos usuários dos serviços de saúde mental e da comunidade em geral. O Quartas Intenções é composto pela comunidade do bairro Rubem Berta, bem como pelos trabalhadores e usuários de serviços de saúde, sobretudo, daqueles vinculados a saúde mental. A dinâmica do Quartas se faz a partir de um assunto do cotidiano escolhido pelos componentes do programa antes de seu início e que é discutido durante seu horário na rádio, sendo dividido em três blocos temáticos separados por músicas selecionadas para o dia. Com as devidas apresentações, entramos agora em mais um encontro real com os amigos imaginários devidamente composto pelos blocos temáticos do Quartas Intenções.

\section{Bloco 1: Pauta Aberta - O Processo \\ De Transformação Do Cuidado Na \\ Saúde Mental}

\author{
Mas louco é quem me diz, \\ E não é feliz, \\ Eu sou feliz! \\ (Arnaldo Baptista \& Rita Lee ${ }^{3}$ )
}

Ao final de 1970, concomitante com os processos de abertura democrática brasileira, ganha força no Brasil o Movimento de Reforma Psiquiátrica influenciado pelos pressupostos da Psiquiatria Democrática Italiana, a qual propôs a substituição dos "manicômios por iniciativas sociais, culturais, políticas, científicas, jurídicas", como, também, transformou a relação do sócius junto "as pessoas portadoras de transtornos mentais" (Pereira \& Pereira, 2003, p.93). A crise do sistema psiquiátrico no Brasil teve vários acontecimentos produtores de transformações que hoje em dia estão em curso, dentre eles, podemos citar a falência do sistema manicomial deflagrado por profissionais e estudantes universitários contratados para trabalhar nos hospitais psiquiátricos, os quais passaram a denunciar a precariedade da assistência aos doentes mentais e as péssimas condições de trabalho a que eram 
submetidos. É nesse contexto que surge o Movimento dos Trabalhadores em Saúde Mental (MTSM), importante e fundamental movimento social no processo da Reforma Psiquiátrica Brasileira. Em paralelo e em consonância com a construção do Sistema Único de Saúde (SUS), a Reforma Psiquiátrica brasileira, toma fôlego nos anos 80 do século passado e inicia uma trajetória de invenção de serviços substitutivos no seio da sociedade acostumada com manicômios.

Nessa Luta, assim como os trabalhadores, os usuários foram protagonistas no processo, que não cessou de ser reconstruído a partir das práticas experimentadas no cotidiano dos serviços substitutivos que se passam no território de vida dos sujeitos em contraposição aos manicômios. Ao invés de um espaço-tempo pautado pelo "trabalho morto", dado e acabado como facilmente observamos nos estabelecimentos manicomiais, a produção dos serviços substitutivos se passa diante de outra ordem, isto é, num movimento de constante travessia, de "trabalho vivo", criado a partir das relações que vão habitando as práticas de cuidado inventadas em "ato" (Merhy, 2002) pelos profissionais, usuários e sociedade. Claro que sempre temos que observar o manicômio em nós, para, mesmo em serviços substitutivos, não estarmos reproduzindo essa ordem que se pretende combater.

O Projeto de Lei $N^{\circ} 3.657 / 89$, do deputado Paulo Delgado, aprovado doze anos após ter sido apresentado e tendo passado por modificações que produziram a Lei 10.216/01, conhecida como a Lei da Reforma Psiquiátrica, veio para consolidar as mudanças propostas, reorientando a Política Nacional de Saúde Mental no Brasil, a qual é baseada na desinstitucionalização da loucura e na desospitalização do cuidado em saúde mental. Proposta que no mínimo visa a cidadania do sujeito com sofrimento psíquico e que deseja promover a ampliação do debate sobre o pensamento antimanicomial entre os vários segmentos da sociedade civil brasileira (Medeiros \& Guimarães, 2002).

Essa construção no legislativo que tem seu berço na produção social em suas lutas por um cuidado diferente em saúde mental, além de redirecionar o modelo de assistência ao torná-lo menos hospitalocêntrico, volta-se para um atendimento territorial-comunitário, no qual garante os direitos individuais dos usuários de ir e vir no cotidiano de suas 
vidas. Nessa perspectiva, inicialmente, são acionados outros dispositivos terapêuticos denominados como serviços abertos, a saber: os Centros de Atenção Psicossocial (CAPS), os Hospitais-Dia, os Residenciais Terapêuticos (RT), dentre outros.

Nesta via que está se constituindo nas últimas décadas, problematizar o campo da saúde mental é, também, pensar sobre a desconstrução de práticas silenciadoras (hospitais psiquiátricos e suas práticas de contenção moral, física e química), para assim construir outras voltadas às necessidades das pessoas com problemáticas em saúde mental. Seria a criação de novas modalidades de atendimento fundamentadas não mais na doença, mas na existênciasofrimento do usuário e na sua relação com a sociedade (Oliveira \& Fortunato, 2007).

Dentro disso, ao longo do processo, foi se percebendo o quanto esse novo modo de cuidar necessitava de expansão em relação aos serviços substitutivos. Expansão que levavam a um cuidado capilar, feito de maneira cada vez mais territorial, comunitário, no qual atingisse os lugares de vida de cada cidadão em sofrimento. Nesse sentido, os CAPS, os Hospitais-dia, os
RTs e outros tantos serviços já não davam conta de todo o processo, se ampliando o cuidado para toda a rede de saúde, bem como para outros setores como a cultura, a educação, os espaços políticos, etc. Instala-se uma forma de “clínica peripatética" (Lancetti, 2007), que se passa numa caminhada pelos territórios existenciais junto a quem sofre, entendendo que ao percorrer tais espaços podem-se produzir novos sentidos, ao invés de somente aprisionar, isolar e, por isso mesmo, minguar cada vez mais a pessoa devido ao sofrimento que apresenta. Como nos comenta um dos usuários que participa do programa sobre esse modo de operar o cuidado: "aqui eu falo de minhas facadas, das drogas e das bebidas. Falo e me escutam como amigos, faço amigos e me sinto bem porque começo a entender toda essa minha vida e ainda estou em contato com as pessoas ${ }^{4, "}$. O que está se configurando é a construção de um novo modo de lidar com o sofrimento mental, acolhendo e cuidando efetivamente dos sujeitos, o que acarreta um outro lugar social para a diversidade e para o sofrimento mental (Amarante, 2007).

Uma das estratégias que veio a somar junto à construção dos serviços substitutivos em saúde mental fora a 
Política Nacional de Humanização (PNH). Bem mais do que fechar os estabelecimentos manicomiais substituindo-os por uma gama diversificada de serviços, ainda se faz necessário, dar conta de outro grande desafio, isto é, tensionar a produção dos manicômios mentais na sociedade. Nesse sentido, a PNH vem dar vazão para essa discussão, problematizando os modos de cuidado no intuito de criar brechas nesse cuidado manicomial ainda tão presente mesmo em serviços substitutivos. Manicômios que percorrem o imaginário do sócius e que faz perseverar nas práticas de cuidado um modus operandi por demais aprisionante, no qual exclui o sujeito em sofrimento de seu próprio processo de vida, só que agora não mais dentro dos hospitais psiquiátricos, mas, a céu aberto.

O cuidado em saúde mental, para além desse modo manicomial, se passa nas relações que vão se processando ao longo dos encontros entre usuários, profissionais e, em última instância, com o próprio mundo. É preciso uma visão de atenção em saúde que rompa com um modelo profissional-centrado, construindo possibilidades de composição e de autonomia junto aos atores envolvidos nessa relação. Nesse sentido, a PNH compreende a necessária valorização dos diferentes sujeitos implicados no processo de produção de saúde em seus territórios existenciais. Destacando-se a autonomia e o protagonismo dos sujeitos, a corresponsabilidade entre eles, os vínculos solidários, a participação coletiva nas práticas de saúde, a mudança nos modelos de atenção e de gestão e a articulação dos processos de formação com os serviços e práticas de saúde (Brasil, 2008).

[...] falamos da humanização do SUS como processo de subjetivação que se efetiva com a alteração dos modelos de atenção e de gestão em saúde, isto é, novos sujeitos implicados em novas práticas de saúde. Pensar a saúde como experiência de criação de si e de modos de viver é tomar a vida em seu movimento de produção de normas e não de assujeitamento a elas (Benevides \& Passos, 2005, p.390).

Nessa perspectiva, o que a $\mathrm{PNH}$ oferece como recurso para a formação, gestão e atenção em saúde é um modo de cuidado pautado por uma constante construção e reatualização das relações que se instalam no cotidiano político que envolve a instituição saúde ${ }^{5}$. Um modo de operar que se faz em travessia, percorrendo as paisagens subjetivas do 
socius no que elas têm de potência para a diferença - o instituinte -, mas, também, no que nelas se encontra por demais enrijecido - o instituído. A PNH se propõe a trabalhar nas diferentes ações e instâncias do SUS, ao mesmo tempo em que abrange diversos níveis da atenção e da gestão. Sua aposta reside na indissociabilidade entre os modos de produção de saúde e de subjetividade, entre os modos de gerir os processos de trabalho e os modos de produzir saúde, entre a clínica e a política (Brasil, 2009).

De tal modo, os desafios multiplicam-se pela complexa realidade dos territórios de saúde no Brasil. A diversidade no campo da saúde implica um modo de fazer singular, construído a cada tear, de maneira artesanal e não numa escala industrial. Com isso, a capilaridade das ações em saúde se dá pelas diferentes articulações, protagonismos e corresponsabilidades que envolvem usuários e profissionais de saúde, assim como o todo da sociedade.

É nesse contexto que a intersetorialidade é destacada nas ações em saúde mental. De acordo com o relatório da IV conferência nacional de saúde mental, o campo da saúde mental é intrinsecamente multidimensional, interdisciplinar, interprofissional e intersetorial. Insere-se no campo da saúde e ao mesmo tempo o transcende, com interfaces importantes e necessárias entre os campos da educação, do lazer, da justiça, do trabalho, da economia solidaria, da habitação, da cultura, do esporte, da assistência social, etc.

\section{Bloco 2: Papo Filosófico - Um \\ Encontro Real Com A Radiodifusão}

\author{
Vida Louca vida. \\ Vida breve, \\ Já que eu não posso te levar, \\ Quero que você me leve! \\ (Lobão \& Bernado Vilhena ${ }^{6}$ )
}

Neste contexto sócio-histórico de proposição de outros modos de cuidado em saúde mental, no qual se propaga as relações de saúde para além do próprio setor, entra em jogo o dispositivo da comunicação social. A radiodifusão comunitária é um importante aparelho social que pode produzir "línguas menores" que interferem na "língua maior" formatadora do que difere de sua proposta homogeneizante ao provocar desvios, "gagueiras" que agenciam outros meios de se comunicar e de criar cultura (Deleuze \& Guattari, 1997). Ela 
"é um lugar privilegiado de distribuição de poder" (Girardi \& Jacobus, 2009, p. 09), de minoridades que se articulam para efetuar brechas num modo de expressar comunicação por demais instituído. A língua menor que aqui comentamos seria a comunicação comunitária, micro-expressividades territoriais que estão vinculadas a realidade da comunidade e, que por conta disso, não produzem uma comunicação distante, muitas vezes, distorcida e mesmo preconceituosa como as transmitidas pela língua maior, isto é, pela grande mídia atravessada por interesses econômicos e políticos em seus noticiários.

[...] cada pessoa pode também comunicar, ou seja, pesquisar, produzir e distribuir informações através de diversos meios de comunicação, abordando assuntos que domina, contando sobre a realidade em que vive, os problemas que ela e seus vizinhos encontram, as novidades que interessam à comunidade. Afinal, as pessoas mais indicadas para falarem sobre determinada realidade são aquelas que a vivenciam. (Girardi \& Jacobus, 2009, p. 10)

A língua menor desliza sobre a maior para agenciar diferenças na língua, invenções que instituem outros possíveis para a comunicação social, num movimento de minoridades que invade as ondas sonoras ao interferir na comunicação de massa - hegemônica. As notícias e opiniões veiculadas na rádio comunitária podem ter a potência de mostrar outras versões do entorno comunitário na maioria das vezes mal falado na grande mídia.

A rádio comunitária, então, está diretamente vinculada com uma programação sintonizada aos problemas da região em que está instalada, com a possibilidade de fomentar a cultura local, num exercício político de cidadania que produz conhecimentos consonantes com a realidade daquela comunidade (Detoni, 2009). Verificamos nas diretrizes básicas de uma rádio comunitária características em consonância aos processos cotidianos da saúde mental. A comunicação comunitária também é capilar, valoriza a vida singular que acontece nos espaços do bairro, imprime uma relação horizontal entre seus atores e tem o entendimento de que a produção democrática é a melhor forma de construir cidadania.

Nessa relação entre rádio comunitária e trabalho em saúde, sobretudo, em saúde mental, vivenciamos como coletivo formador do 
Quartas Intenções, um outro possível no modo de operar o cuidado. Ao transmitirmos o programa éramos loucutores $^{7}$, uma mistura que acontecia entre os participantes e que não mais discernia quem era morador do bairro, usuário ou profissional de saúde e técnico de rádio. Um cuidado $\mathrm{e}$ comunicação transversal que atravessava a todos na produção de um espaço comunicacional terapeutizante junto aos envolvidos, isto é, os loucutores e os ouvintes do programa. Além disso, experimentamos uma outra forma de comunicar, uma maneira de expressar pelas ondas sonoras as problemáticas que estávamos envolvidos sem um grande mediador, a saber, a mídia hegemônica docilizadora e direcionalizadora das informações veiculadas nos grandes meios de comunicação.

\section{Bloco 3: Palavras De Vida - Propagar Eletromagneticamente As Ondas Sonoras Da Loucura!}

Toquem о теи coração,

Façam a revolução,

Que está no ar, nas ondas do rádio,

No submundo repousa o repúdio

E deve despertar.

(Paulo Ricardo ${ }^{8}$ )
A radiodifusão pode ser entendida como a transmissão de ondas de radiofrequência moduladas que se propagam eletromagneticamente pelo espaço. Suas ondas sonoras percorrem o mundo e são captadas através da escuta de seus ouvintes, sendo experimentadas como um amigo sonoro que vem fazer companhia àqueles que estão conectados na frequência. Zonas de interferência se produzem entre os loucutores e seus ouvintes, composição de pensamentos que permeiam o imaginário dessa rede comunicativa.

Rede comunicativa de interferência mútua é o que podemos observar também nas práticas de cuidado em saúde quando são entendidas como "trabalho vivo" (Merhy, 2002), em produção constante de travessias inventivas no fazer clínico. É numa zona de interferência, de passagem para a alteridade, que se vislumbra a construção das relações no cuidado em saúde, as quais ao longo do tempo podem ir se diferenciando a partir das singularidades expressas nos encontros.

A PNH parece sensível para tal modo de operar numa clínica política de ampliação da vida, constituindo-se a partir de um Método denominado como Tríplice Inclusão: inclusão de sujeitos, 
de coletivos e de perturbação que essas inclusões produzem nos modos de gerir os serviços de saúde e as relações clínicas.

[...] essa última inclusão se apresenta como a mais importante do ponto de vista ético: inclusão da diferença, suportando-a e, ao mesmo tempo, tornando-a como principal força-motor da produção de mudanças, que em última instância, são as atitudes e comportamentos das pessoas (Pasche, 2012, p.33).

A radiodifusão, sobretudo a comunitária, se torna um importante dispositivo de inclusão da diferença, das coletividades com pouco valor expressivo dentro de uma comunicação hegemônica. Da mesma forma, é um espaço que amplia a concepção do cuidado em saúde, perturbando seu entendimento ao explorar relações outras que também permeiam a vida de qualquer transeunte.

Uma situação no início das atividades radiofônicas do Quartas Intenções pôde nos mostrar essa perturbação em ato na concepção do cuidado em saúde. Ao planejarmos os primeiros programas que iriam ao ar, discutimos a questão de como nos apresentar aos ouvintes. Alguns questionavam: apresentaremos-nos como profissionais da saúde e como pacientes? Um dos integrantes, então, logo apontou que não queria se apresentar como paciente e essa pontuação foi essencial para a construção do que queríamos ser, no caso: loucutores de um programa de rádio comunitária e não pacientes ou profissionais da saúde. "Tínhamos que arrebentar nossas caixinhas" como comentara um dos participantes do programa! Afinal, entendíamos que não seria potente nos restringir a papéis tão identitários advindos dos serviços de saúde que ali eram diluídos por práticas culturais e de comunicação. E, como afirmamos, nos denominaríamos como loucutores, numa mistura de loucura com a prática de locução na rádio, expressando a vontade de fazer um programa louco no sentido potente da palavra, isto é, no que a loucura nos oferece como inesperado, incontrolável e que suscita a invenções nos debates radiofônicos. Desde então, todos são loucutores e se apresentam com os próprios nomes, com as devidas singularidades que com isso se expressam.

As relações que percorrem 0 fazer rádio expandem os modos de ser, indo para um além do que se consegue 
compreender quando se visualiza a saúde de maneira isolada na produção de cuidado.

[...] no contexto da rede de serviços todos conhecem a história de vida daquele sujeito e, portanto, todos os detalhes de sua enfermidade. Esse conhecimento, necessário ao trabalhador para uma oferta adequada de cuidado, produz também, ainda que involuntariamente, uma obstrução do trabalho, já que termina por antecipar posturas e condutas do usuário. Já nas redes sociais de baixa densidade não encontramos este conhecimento prévio sobre o sujeito, possibilitando que ele possa ser para além do enfermo, que possa se apresentar de distintas maneiras, favorecendo a ocupação de outros lugares sociais (Palombini, Cabral \& Belloc, 2008, p. 07).

O processo de cuidado acontecido nas ondas do rádio embaralha as identidades postas classicamente, ou seja, as posições dos terapeutas e dos pacientes circulam por outros lugares, por outras produções de ser, como a do planejador do programa, a do locutor, a do amigo de trabalho, etc. Nesse sentido, os integrantes do Quartas Intenções são muito mais atravessados por esses outros possíveis do ser do $q^{1}$ ue por essa relação terapeuta-paciente já tão cotidianizada e relacionada às impotências patológicas que os serviços de saúde percorrem a fim de uma possível cura. Nessas ondas sonoras que invadem o cotidiano, há espaço para a expressão daqueles que por anos ficaram trancafiados em manicômios concretos ou mentais, estigmatizados como seres sem razão e de comportamentos perigosos. No processo radiofônico, é permitido aos antigos pacientes a colocação de suas ideias para o mundo, com as quais constroem um outro lugar para além das patologias que os engessavam como as camisas de força tão desgastadas.

Uma outra cena rememorada que queremos compartilhar aqui no escrito, se passa quando num dos programas conversamos sobre a possibilidade de sermos atropelados. Um dos integrantes do Quartas tinha passado por isso e foi interessante poder pautar tal assunto, que se multiplicou para muitas formas de pensar um atropelo na vida, do concreto ao simbólico e vice-versa, num movimento que trazia espontaneidade e liberdade para o debate. E a pergunta que não quis calar nesse encontro poderia ser resumida assim: quem nunca foi atropelado na vida?

Trazemos esse encontro à tona, pois, percebemos que ao longo dos programas que fomos apresentando, um 
processo potente de inclusão, de perturbação no cotidiano pronto, se produzia à medida que íamos vinculando assuntos que têm a ver com cada integrante da equipe. Os assuntos atravessam a produção de vida de cada um, do lugar que cada loucutor se encontra, partindo para uma outra composição a partir das discussões que vão se dando ao longo dos programas de rádio. Cada um se refaz a partir do assunto que está sendo pautado e construído no coletivo comunicacional.

E esse processo potente de inclusão de perturbações nos modos de ser na vida, pode-se diluir em algumas características que se operam de acordo com a proposta do programa Quartas Intenções. Num primeiro momento, se abre a possibilidade de incluir os envolvidos com o programa quando planejamos o mesmo, ao pensarmos o que irá ao ar os loucutores criam intercessões e proposições para a futura transmissão que atingirá determinado público ouvinte. Também, nesse processo de apresentação do programa, é notória a invenção de si que ocorre em ato a cada encontro, nos quais há de se fazer um esforço para criar pensamentos sobre o que está em pauta. Em seguida, outra inclusão comunicativa se passa quando aqueles que recebem a programação podem interagir com o programa, comentando se estão gostando, se discordam ou concordam com o que está sendo debatido e propondo outras falas. No caso, a comunidade ouvinte é capaz de interferir direta ou indiretamente naquilo que é dito com a possibilidade de protagonizar novas discussões e temas de interesse. Espécie de "comunicação terapeutizante de (re)significação dos sentido de vida, que estimula redes de conexão que estavam esquecidas ou não acionadas" (Moreira, 2011). Comunidade ouvinte e loucutores interagindo e interferindo na rede conectiva da vida a partir da radiodifusão.

Com o decorrer dos encontros radiofônicos, fomos construindo e sintonizando as ondas sonoras, algumas vezes, receosas de falar no microfone para o mundo, com silêncios que percorriam o andamento do programa retratando um pouco da inexperiência de expressar as próprias opiniões que rondavam o imaginário de cada um. Contudo, aos poucos alçamos voos inusitados pelas expressividades que cada integrante ali ofertava, com as quais se tornou possível produzir debates que transformavam cada um que se arriscava a falar ao microfone, o 
que diluía as hierarquias que poderiam pairar pelo programa. Era um esquecimento em ato dos lugares identitários que cada um tinha chegado no começo da rádio que ali se processava, rumo a novas conexões de mundo.

Nesse voo livre, escolhemos previamente algumas ondas, mas, a partir delas construímos algo singular na composição dos pensamentos que o coletivo da rádio experimentava em seu cotidiano de trabalho. Nesse sentido, podemos dizer que, via ondas sonoras, foi nos permitido pensar uma outra inscrição para o entendimento da loucura e para o sofrimento psíquico, numa tentativa de transformar os diversos entraves que ainda pautam o campo da saúde mental, como: a distância entre os usuários e os cuidadores, sendo permitido um outro tipo de aproximação durante os programas de rádio, com outros efeitos terapêuticos e de potência de vida. Da mesma forma, a aproximação do cuidado em saúde mental junto à comunidade, a cultura, enfim, ao território de vida das pessoas, se mostra primordial para se pensar à atenção em saúde. O que, em nosso entendimento, pode permitir uma capilarização do pensar o que é sofrer psiquicamente junto à sociedade, diluindo as estereotipias que vemos rondar o imaginário em sua produção de manicômios mentais existentes até os dias de hoje.

\section{Mensagem Final: Dicas Do Dia}

A constituição do Programa de Rádio Quartas Intenções nasceu devido ao desejo de uma prática direcionada à comunidade e aos seus dispositivos socioculturais, na intenção de potencializar a vida de quem viesse a participar de tal proposta radiofônica. Em se tratando do cuidado em saúde mental, nos parece sempre importante dar espaço para parcerias como essas que experimentamos com o programa de rádio. Comunicação, saúde e produção cultural em composição permitem ampliar as ações de atenção à saúde num movimento de reconhecimento do ser humano em sua integralidade e complexidade. A saúde como processo dinâmico e a cultura como espaço de realização humana em suas várias manifestações se agenciam para uma ampliação da clínica, da gestão do cuidado e, em última instância, da vida.

A cultura, enquanto estratégia inventiva do homem, produz mundos 
para lidar com as limitações e sofrimentos que angustiam o ser humano, sendo um importante aspecto nos processos terapêuticos de qualquer pessoa. Até porque é na cultura e por conta dela que adoecemos e, sem dúvida, é somente num movimento de criação cultural que podemos diversificar a cultura posta, normatizada, que estigmatiza alguns amparada num modelo ideal produzido. Lembremos-nos das palavras de Canguilhem (1990), em seu "O Normal e o Patológico", quando ele descreve o quanto a produção de doença numa determinada sociedade pode ser vista como algo extremamente potente em um outro sócius com diferentes valores.

O espaço radiofônico possibilita o ato de produzir cultura através das falas, dos pensamentos trocados e da diversidade que ocorre na relação loucutor-ouvinte, com as ondas sonoras invadindo as paisagens subjetivas em trânsito no conjunto da sociedade. A valorização do usuário, ou melhor, a sua "transvaloração" como nos diria Nietzsche (2003), permite uma abertura para que a loucura ocupe outro lugar na cultura e no território, rompendo com os estereótipos de perigo e de desrazão que ainda circundam no imaginário social. Dessa forma, é possível pensar outros modos de se relacionar com a loucura e com suas fragilidades, deslocando determinadas identidades que mais produzem adoecimentos do que qualquer outra coisa, num movimento de transformação dos valores postos em jogo pela cultura.

Decorridos aproximadamente três anos dessa experiência radiofônica, podemos observar o quanto se construiu em relação a um projeto de cuidado em saúde, especialmente, em saúde mental. Novas referências de cuidado atravessadas pela intersetorialidade nos permeiam enquanto cuidadores e usuários diante do cenário posto. Se imaginávamos intervir num espaçotempo definido no cuidado em saúde, nos enganamos, pois, é notório o quanto não sabemos a dimensão que um encontro com a alteridade pode produzir na medida em que o ambiente é contagiado ao caminhar por lugares até então impensáveis. No trabalho em saúde, somos convocados a intervir, só que nem sempre estamos atentos às interferências que repercutem em nós mesmos, o quanto sofremos transformações quando dispostos estamos para o processo relacional.

De tal modo, que esta experiência da radiodifusão reflete a dupla repercussão no agir em saúde, no 
qual se pulula reverberações no usuário que expande seu repertório existencial para além das doenças, assim como ocorre o mesmo com os cuidadores que ampliam sua visão de saúde e, até mesmo, se permitem compartilhar o cuidar junto aos usuários agora colegas de rádio, amigos de vida.

Por fim, nosso programa se propõe a ir além das segundas e terceiras intenções, ele quer mais, múltiplas intencionalidades, intensidades que se agenciam na produção de uma coletividade que exige seu espaço, seu mundo singular em composição com a cultura posta a fim de modificá-la. A aposta do programa é fazer uma rádio reflexiva, de descoberta do novo através do cotidiano ali colocado na mesa de conversa, dos encontros entre as diferentes ideias que surgem, num lançar interrogações ao contrário de apenas afirmar respostas. Boa tarde e até o próximo encontro radiofônico!

\section{Notas}

\footnotetext{
Tste texto é inédito, composto por trabalhadores, residentes e usuários dos serviços de saúde de Porto Alegre e não contém nenhum conflito de interesse. $\mathrm{O}$ texto em si não possui financiamento e parte de uma iniciativa política de seus
}

autores de publicizar um modo de pensar o cuidado. E ele é resultado dos encontros do grupo que participa do Programa Quartas Intenções, não sendo especificamente ligado a algum tipo de trabalho de conclusão de mestrado, doutorado, residência, etc.

${ }^{2}$ Para situar o cenário aqui apresentado é interessante apresentar o GHC, vinculado ao Ministério da Saúde do Brasil. O GHC possui uma ampla rede de saúde mental comparada ao da cidade de Porto Alegre e administrada pela prefeitura, tendo: CAPSII, CAPSadIII, CAPSi, Consultório na Rua, Gestores do Cuidado, ambulatório psiquiátrico e internação no Hospital Conceição. Além dos serviços propriamente da saúde mental, ainda possui uma vasta rede de atenção primária e terciária, destacando-se quatro hospitais e doze Unidades Básicas de Saúde que estão em relação com os serviços de saúde mental, materializando intervenções no território do usuário. É importante destacar os pontos de cultura que se vinculam a rede de atenção à saúde e o próprio Chalé da Cultura do Hospital Conceição que possibilitam a promoção de saúde a partir de ações intersetoriais junto à cultura. 
${ }^{3}$ Banda Mutantes, sexta faixa, Música

Balado do Louco, Álbum Mutantes e Seus Cometas no País do Baurets, 1972.

${ }^{4}$ Fala pronunciada num dos Programas do Quartas Intenções.

5 Entendemos por Instituição o que “impõe ao nosso corpo, mesmo em suas estruturas involuntárias, uma série de modelos, dando à nossa inteligência um saber, uma possibilidade de prever e de projetar" (Deleuze, 2006, p. 31). Isto é, um sistema de antecipação que abocanha os atos de inovação para assim termos o mesmo já devidamente controlado. O instituído é a forma dura da instituição que se auto-reproduz pela igualdade, pelos costumes postos, já o instituinte se faz das forças movidas pela alteridade, no caso, pela diferença que impõe um jogo de forças rumo à transformação da instituição.

6 Lobão, Música Vida Louca vida, sétima faixa do Álbum Vida Bandida, 1987.

${ }^{7}$ Loucutores foi o modo que passamos a nos chamar nos programas. No momento apropriado voltaremos a pensar sobre esse nome que perpassa a todos no Quartas Intenções.

8 Banda RPM, Música Rádio Pirata, Álbum Revoluções por Minuto, 1985.

\section{Referências}

Amarante, P. (2007). Saúde mental e atenção psicossocial. Rio de Janeiro: Editora Fiocruz.

Benevides, Regina \& Passos, Eduardo. (2005). Humanização na saúde: um novo modismo? Revista Interface - Comunicação, Saúde, Educação. São Paulo, 9(17), 389394.

Brasil. (2008). Ministério da Saúde. Política Nacional de Humanização. Documento base para gestores e trabalhadores do SUS. (4⿳亠口冋. Ed.). Brasília: Ministério da Saúde.

Brasil. (2009). Ministério da Saúde. Política Nacional de Humanização. Trabalho e Redes de Saúde. Brasília: Ministério da Saúde.

Brasil. (2009a). Ministério da Saúde. Secretaria de Assistência à Saúde. Humaniza SUS: Redes de Produção de Saúde. ( $1^{\text {a }}$ ed.). Brasília: Ministério da Saúde.

Canguilhem, G. (1990). O normal e o patológico. Rio de janeiro: Forense Universitária.

Detoni, Márcia. (2009). Radiodifusão Comunitária: Baixa Potência, Altas Mudanças? O potencial das 
emissoras comunitárias como instrumento de transformação social. Mídia Cidadã 2009 - V Conferência Brasileira de Mídia Cidadã, Guarapuava, 864-883.

Deleuze, Gilles \& Guattari, Félix. (1997). Mil Platôs - Capitalismo e Esquizofrenia (vol. 2; P. P. Pelbart e J. Caiafa Trad.). São Paulo: ED 34.

Deleuze, Gilles. Instintos e instituições (1955). In A ilha deserta: e outros textos. Edição preparada por David Lapoujade: organização da edição brasileira e revisão técnica Luiz B. L. Orlandi. - São Paulo: Iluminuras, 2006.

Girardi, Ilza \& Jacobus Rodrigo. (2009). Para fazer rádio comunitária com " $C$ " maiúsculo. Porto Alegre: Revolução de Ideias.

Lancetti, Antonio. (2007). Clínica peripatética. (SaúdeLoucura; 20. Série Políticas do desejo; 1). São Paulo: Hucitec, 2007.

Medeiros, S. M. \& Guimarães, J. (2002). Cidadania e saúde mental no Brasil: contribuição ao debate. Ciência e Saúde Coletiva, 3 (3), 571-579.
Merhy, Emerson Elias. (2002) Saúde: a cartografia do trabalho vivo. (Saúde em Debate). São Paulo: Hucitec.

Moreira, R. (2011). Projeto Maluco Beleza: a comunicação como dispositivo terapeutizante de (re)significação de sentido de vida, no contexto da reforma psiquiátrica. Tese (Doutorado). Escola de Comunicação e Artes, Universidade de São Paulo, São Paulo.

Nietzsche, Friedrich. (2003). Ecce Homo: como cheguei a ser o que sou. (P. Nassetti, Trad.). São Paulo: Ed. Martin Claret.

Oliveira, F. B. \& Fortunato, M. L. (2007). Reabilitação psicossocial na perspectiva da reforma psiquiátrica. Rev. Vivência, 32, Natal/RN, 155-181.

Palombini, Analice de Lima; Cabral, Karol Veiga \& Belloc, Márcio Mariath. (2008). Dispositivos clínicos em saúde mental: a clínica na cidade entre o acontecimento e a permanência do AT à radiodifusão como estratégia de ocupação da cidade. III Congresso Brasileiro de Psicopatologia Fundamental, Niterói. 
Pasche, Dário Frederico. (2011). Pistas metodológicas para se avançar na humanização dos hospitais no Brasil. In Brasil. Ministério da Saúde. Secretaria de Atenção à Saúde. Departamento de Ações Programáticas e Estratégicas. Cadernos Humaniza SUS. (Vol.3). Brasília: Ministério da Saúde.

Pereira, M. A. O. \& Pereira, A, J. (2003). Transtorno mental: dificuldades enfrentadas pela família. Rev. Esc. Enferm. USP, São Paulo, 37(4), 92-100.

Sistema Único de Saúde. (2010). Conselho Nacional de Saúde. Comissão Organizadora da IV Conferência Nacional de Saúde Mental - Intersetorial. Relatório Final da IV Conferência Nacional de Saúde Mental - Intersetorial. Brasília: Conselho Nacional de Saúde/Ministério da Saúde.

Ariane Marinho Santana: Terapeuta ocupacional, atualmente é residente no Grupo Hospitalar Conceição (Porto Alegre - RS), na área de saúde mental.

E-mail: a.marinho03@gmail.com

\section{Carlos Alberto Severo Garcia Júnior:}

Psicólogo, mestre em Educação, atualmente doutorando do Programa
Interdisciplinar em Ciências Humanas (UFSC). Membro do Núcleo de Pesquisa em Bioética e Saúde Coletiva (NUPEBISC/UFSC). Consultor da Política Nacional de Humanização (PNH), pelo Ministério da Saúde (MS), em Santa Catarina (SC).

E-mail:

carlosgarciajunior@hotmail.com

\section{Mário Francis Petry Londero:}

Psicologo, mestre em Psicologia Social e Institucional e graduando em Ciências Sociais pela Universidade Federal do Rio Grande do Sul (UFRGS). Pesquisador do grupo INTERVIRES do Programa de Pós-Graduação em Psicologia Social e Institucional UFRGS. Residente em psicologia na Residência Integrada em Saúde pelo Grupo Hospitalar Conceição - ênfase em saúde mental.

E-mail: francislonder@hotmail.com

Milene Calderaro Martins: Terapeuta ocupacional,atualmente trabalha no Grupo Hospitalar Conceição na área de saúde mental.

E-mail: mila.calderaro@gmail.com 


\section{Michele dos Santos Ramos Lewis:}

Psicóloga, graduada pela Universidade Federal de Santa Maria. Atualmente é residente do programa de Residência Integrada em Saúde com ênfase em Saúde Mental do Grupo Hospitalar Conceição - Porto Alegre, Rio Grande do Sul.

E-mail: micheleramos.rs@ gmail.com

Renato Luiz Rieger da Nova: Artesão, pintor, músico e artista plástico, participa de eventos ligados a arte na capital porto-alegrense e do projeto Rodas de Conversa: Saúde e Cultura do GHC.

E-mail: renatoarte777@gmail.com 